\title{
When sanctions convey moral norms
}

\author{
Laetitia B. Mulder ${ }^{1}$
}

Published online: 2 March 2016

(C) The Author(s) 2016. This article is published with open access at Springerlink.com

\begin{abstract}
Sanctions not only have the instrumental function of deterring people from undesired behavior but they also have the ability to convey moral norms. As such, they may create a moral motivation not to engage in the sanctioned behavior. This is desirable as this makes the success of a sanctioning system depend less on quality of enforcement. However, sanctions may not always succeed in conveying moral norms. In this paper, three conditions are highlighted that, in the psychology literature, have been empirically proven to influence whether a sanction succeeds to evoke moral norms. First, a sanction should not be regarded as a way to make up for the negative consequences of a transgression a sanction. So, they should be communicated in a retributive way rather than in a compensatory way. Second, as punishments communicate an obligatory rule and rewards communicate a voluntary rule, punishments are a better way to incur moral norms than rewards. Third, severe sanctions more strongly convey a moral norm than mild ones as long as these severe sanctions are not unreasonably severe, are installed by trustworthy authorities and in a fair way. The value of the moral expressive function of sanctions, as well as its drawbacks, are discussed.
\end{abstract}

Keywords Sanctions · Morality · Punishments · Rewards · Norms

JEL Classification $\mathrm{K} 00 \cdot \mathrm{K} 1 \cdot \mathrm{K} 2 \cdot \mathrm{K} 4$

Laetitia B. Mulder

1.b.mulder@rug.nl

1 Department of HRM\&OB, Faculty of Economics and Business, University of Groningen, P.O. Box 800, 9700 AV Groningen, The Netherlands 


\section{Introduction}

A frequently used way to discourage citizens to engage in undesirable behaviors such as illegal downloading, tax evasion or speeding, is sanctioning those behaviors. By installing a sanctioning system, policy makers base their decision on the idea that a sanction changes the attractiveness of the behavior, which deters people to engage in it. This utilitarian view of punishment has been around since Beccaria (1775) and was advocated by many, including Becker (1993).

However, research has increasingly paid attention to the role that norms play in citizen's behavior and has yielded insights that are difficult to reconcile with a pure utilitarian view. For example, tax literature has shown that the majority of people pay their taxes while actually the chances of getting caught when you do not pay taxes, are low (Torgler and Schneider 2005). This illustrates that people pay taxes based on internalized norms such as "tax morale" (Torgler and Schneider 2005) or a feeling of duty (Scholz and Pinney 1995). In criminology it has been advocated that the interplay of moral norms and instrumental incentives should be taken into account. Kroneberg et al. (2010) concluded that shoplifting and tax fraud was only based on instrumental rationality for people who did not feel bounded by moral norms. For those with strongly internalized norms, instrumental incentives had no influence. In line with this, Wenzel (2004) showed that sanctions only influenced tax compliance when personal tax-paying norms where low.

Thus, next to sanctions, moral norms importantly determine behavior as well. However, it may be a mistake to regard the topic of sanctions and moral norms as two independent entities. In fact, sanctions may give shape to moral norms and vice versa. After all, sanctions do not only have the instrumental purpose of deterring people from the undesired behavior, but also have a retributive, "just deserts" function (Carlsmith et al. 2002; McFatter 1982; Watamura et al. 2014) which entails that a sanction is seen as a measure to restore an injustice done. Indeed, although often implicit, preference for punishment is often morally-driven (Bilz and Nadler 2009; Wiltermuth and Flynn 2013), stemming from moral emotions (Darley and Pittman 2003; Ellsworth and Gross 1994) or from normative evaluations of an act (Warr et al. 1983). Thus, the inclination to punish a certain type of behavior stems from the idea that engaging in this behavior is "morally wrong". Similarly, the installation of a sanctioning system has an expressive function of showing what is morally right and wrong (McAdams 2000) as one communicates that the behavior is morally disapproved of and that perpetrators of the rule are morally condemned (Cooter 1998). People may perceive this moral disapproval as stemming merely from the authority who installs the sanction. However, since an authority usually represents a larger society, a sanction may more generally signal that the group or larger society disapproves of the sanctioned behavior. As such, sanctions provide social validation for rules and may actually foster the moral conviction that the sanctioned behavior is "bad" (Williams and Hawkins 1986; Yanagida and Fujii 2004). This expressive function of sanctions may partly explain why sanctions steer behavior. Indeed, in the context of trade secret law, Feldman (2009) has shown that laws steer people's behavior because they make people perceive the undesired act as 
immoral. In the same line, Thøgersen (2008) showed that the effect of economic incentives on recycling garbage could largely be explained by a change in personal norms favoring recycling.

The above suggests that a sanction may not only work by making the sanctioned behavior objectively less attractive, but also by, due to its expressive function, creating a moral motivation not to engage in the sanctioned behavior. Nevertheless, sanctions may not always succeed in this. In fact, there is also literature that suggest that sanctions have the opposite expressive function (Fehr and Falk 2001; Gneezy and Rustichini 2000; Tenbrunsel and Messick 1999) and may actually undermine moral norms. A nice illustration of this is the study of Gneezy and Rustichini (2000) in which a child day-care center installed a fine for picking up one's children late. This induced parents to pick up their children even later as they suddenly regarded the situation as a business transaction: In exchange for them paying the fine, their children were cared for a bit longer. In line with this, data of Mulder and Van Dijk (work in progress) shows that the presence of a fine can reduce feelings of shame and guilt after showing the undesired behavior.

Thus, sanctions have the ability to positively affect the morality of a decision (by communicating a moral norm), but they may also fail to do so (and even negatively affect morality by transforming an ethical issue into a business transaction). Whether or not sanctions affect morality in a positive way, may depend on various circumstances. Research has identified several moderators of a sanction's effect on morality. In this paper, we draw from the psychology literature and highlight three factors that have been shown to determine the symbolic function of sanctions. The first is the extent to which a sanction is communicated as a form or retribution rather than as a form of compensation. The second is whether a sanction takes the form of a punishment or a reward. The third is the severity of a sanction.

\section{Retribution versus compensation}

As is suggested in the argumentation above, the way a sanction affects moral norms is determined by how a sanction is perceived. Sanctions may sometimes be seen in a retributive way, meaning that they are regarded as a way for punishing the trespassing of a moral norm. At other times, sanctions may be seen in a compensatory way, meaning that they are regarded as a way to make up for the negative consequences of a transgression. When a sanction is interpreted as retributive rather than compensatory in nature, it is thus more likely to have a moral connotation and thus induce a moral norm (Kurz et al. 2014; Mulder 2009). Hence, the way a sanction is communicated may matter a lot: When it is communicated as a way to punish and discourage undesired behavior, it is more likely to communicate a moral norm than when it is communicated as a way to compensate for the consequences of the undesired behavior.

Empirical support for this was found by Kurz et al. (2014) who showed that merely framing a sanction in either a retributive or a compensatory way, induces different behavioral effects. In their studies, a financial sanction was imposed on students arriving late for an experiment (in which they earned a $£ 2$ participation 
fee). The sanction was either announced by using retributive wordings or by using compensatory wordings. More specific, in the retributive condition students read: "Latecomers will cause large inconveniences. For this reason, latecomers will forfeit their $£ 2$ if more than 15 min late". In the compensatory condition, students read: "Arriving late may hamper our ability to complete the session, which will have financial implications for the research project. As a means to compensate for this, latecomers will forfeit their $£ 2$ if more than 15 min late". It turned out that students who read the retributive wording arrived earlier for the experiment than students who read the compensatory wording. In fact, $80 \%$ of the students in the retributive condition were on time compared to $60 \%$ in the compensatory condition. In a second study Kurz, Thomas and Fonseca showed that, when a fine for late-coming was framed in a retributive way, people experienced late-coming to a greater extent as a moral transgression than when the fine was framed in a compensatory way.

Data of Mulder and Van Dijk (work in progress) who focused on a sanction's effect on self-conscious emotions, are in line with this. In a public library, clients of the library read about fines for returning books late. The explanations for the fine differed. One group of clients read that the fine was there to "finance the extra borrowing time" of the books returned late, whereas the other group read that the fine was there to "discourage people to rent books longer". Naturally, clients who were late with returning books felt more guilty and ashamed than clients who were not late with returning books. However, this was only the case when the fine was presented as a discouragement rather than as a financial compensation. Thus, presenting a fine as financial compensation prevented people from feeling bad about showing the undesired behavior.

\section{Punishment versus reward}

The word "sanction" is associated with something negative, namely a punishment for undesired behavior. However, one may also use rewards in order to encourage desired behavior. There is indication that both punishments and rewards are effective in influencing people's behavior. For example, in social dilemmas (situations in which people face a choice between benefiting the collective good and benefiting the self-interest) (Dawes 1980), a punishment for choosing for the selfinterest has appeared to induce people to choose for the collective good to an equal extent as rewarding a choice for the collective good (see Balliet et al. 2011, for a meta-analysis). Nevertheless, the psychological effects of punishments may be very different from that of rewards. Punishments are more coercive in nature than rewards and thus harm the decisional feeling that people experience (Deci et al. 1999). One side of this is that a punishment can lead to negative emotions, retaliation and psychological reactance (Wit and Wilke 1990), whereas the use of rewards results in openness, feelings of acceptance and positive attitudes towards the power holder (Tjosvold 1995).

However, another side of punishment is that they are more likely to communicate a moral obligation than a reward. Exactly because a punishment is more coercive, it 
is likely to communicate an obligatory rule, whereas a reward is likely to communicate a voluntary rule. The distinction between obligatory and voluntary rules was made by O'Gorman et al. (2005) and is comparable to Kant's distinction between perfect and imperfect duties (Kant 1797/1991). Obligatory rules are considered as inviolable or unconditional: one should always follow the rule in order to be moral. In contrast, voluntary rules refer to morally praiseworthy behavior that is not necessarily required. By introducing a punishment for engaging in the undesired behavior (rather than a reward for engaging in the desired behavior), an authority communicates that the desired behavior is obligatory rather than voluntary and that the undesired behavior is morally disapproved of. As such, punishments are more likely to trigger moral concerns than rewards.

This was indeed found by Mulder (2008). In this paper, two studies were performed to test the symbolic effects of punishments versus rewards. In the first study, people played a social dilemma game in which they faced the decision to give money to the group or keep it for themselves. One group was told that, in these type of games, punishments for not contributing to the group were common, whereas another group was told that rewards for contributing to the group were common (to purely test for the symbolic rather than instrumental effects of sanctions, actual punishments or rewards were not given). The results showed that the group that was told about punishments contributed more to the group than the group that was told about the reward. Also, the punishment group expressed more moral concerns about the situation than the reward group. In the second study, people were confronted with another person who either had shown selfish behavior in a situation where there was a punishment for selfish behavior or in a situation where there was a reward for cooperative behavior. People in the punishment situation, compared to people in the reward situation, showed stricter moral judgments about selfish behavior and more social disapproval of an individual who acted selfishly. Thus, this research shows that punishments evoke stronger moral concerns than rewards and makes people judge others who show the undesired behavior more negatively.

\section{Severity of sanction}

Logically, large sanctions are more deterring than small ones. For example, in a study among business entrepreneurs, Goslinga and Denkers (2009) showed that law complying intentions were higher when sanctions were severe rather than mild. Still, criminology literature has argued and found that compliance with laws depends more on punishment certainty rather than harshness (Jacobs and Piquero 2013; Piquero et al. 2011; Pratt et al. 2006). For example, research by Varma and Doob (1998) among Canadian tax payers found that perceived penalties were less important determinants of tax evasion than perceptions of possibility of being apprehended.

Based on this, one may be inclined to conclude that policy makers should only aim at increasing detection probability and not worry about increasing sanction size. However, this conclusion is premature as sanction severity may be more than only a factor of deterrence. It may also determine a sanction's success in conveying a 
moral norm. As serious crimes are usually sanctioned more severely than small crimes, the size of a sanction attached to a rule may actually communicate how serious it is to break the rule, and thus, how immoral rule breaking behavior is. Thus, people may infer from the size of a sanction how much the sanctioned behavior is morally disapproved of and adopt this moral standpoint themselves. This was tested by Mulder et al. (2009). They found that, when non-cooperative choices in a social decision situation were fined, a moderately large fine made people morally disapprove of the non-cooperative behavior more than a small fine.

Interestingly, the effect of sanction size on moral disapproval did depend on the extent to which people trusted the authority. For example, in one of Mulder et al. (2009) studies about cheating during an exam, students were either told about a mild sanction (a small inconsequential rebuke) or a severe sanction (being expelled from the exam and, if repeated in future, expelled from their studies). Also, their trust in the educational institution was measured. Results showed that, only when trust in the educational institution was high, the severe sanction induced more moral disapproval towards cheating than the mild sanction. The explanation for this was that people only adopt moral disapproval as expressed by an authority introducing a large sanction, when this authority is regarded as trustworthy. After all, if an authority is experienced as trustworthy, (s)he is more likely to be perceived as able to judge what is moral and what is not, and to sincerely express his or her moral convictions without having a hidden self-interested agenda. Also, the fairness of the procedures of the sanctioning system matter, as was illustrated by Verboon and Van Dijke (2011). In their study, students were exposed to mild or severe sanctions for plagiarism and to procedures that were fair (the rules applied for all students) or unfair (the rules applied for only a subset of students). A severe sanction increased compliance intentions only in case the procedures were fair.

Thus, severe sanctions are more likely to incur moral norms than mild ones, as long as they are implemented by a trustworthy authority and in a fair way. It is important to note that the severe sanctions in the above described studies were severe but only to the extent that this was reasonable. A disproportionally large sanction can actually fail to increase moral norms, and may even backfire, as it is perceived as unjust. For example, it has been found that excessive legal sanctions in copyright law decrease the norm that copying music is wrong (Depoorter and Vanneste 2005). Thus, the severity of a sanction may induce moral norms only up to a point: as long as the sanction is perceived as reasonable, people accept the communicated message that the sanctioned behavior is immoral. But as soon as the sanction becomes unreasonably severe, people will not be receptive to this message anymore.

\section{Discussion}

Sanctions can be more than mere instrumental means to deter people from undesired behavior. By expressing what is right and wrong, they are able to communicate moral disapproval regarding the undesired behavior and, as such, may induce moral norms. However, for this to happen, several conditions need to be fulfilled. This 
paper highlighted three conditions that were found, in psychological empirical literature, to be relevant. First, a sanction needs to be communicated in a retributive rather than in a compensatory way. When installing a sanction, it should be clear that the sanction is in place to discourage the sanctioned behavior to occur and not to compensate for the negative consequences of the undesired behavior. Second, punishments are a better way to incur moral norms than rewards. Because punishments communicate a rule that is more obligatory than voluntary, they are more successful than rewards in showing moral disapproval and in conveying that the undesired behavior is morally wrong. Third, severe sanctions more strongly convey a moral norm than mild ones. That is, as long as these severe sanctions are installed by trustworthy authorities and in a fair way. Also, they should not be unreasonably severe.

The power of sanctions to incur moral norms greatly adds to the preventive function that sanctions have. After all, people are motivated to see themselves as moral beings and act in ways that are consistent with this self-view (Aquino and Reed 2002; Blasi 1983, 1984). So, if a sanction creates the idea that it is immoral to engage in certain behavior, people will abstain from this behavior. Moreover, sanctions that succeed in conveying a moral norm may be more impervious to suboptimal enforcement. After all, it is usually infeasible and undesired to monitor people's behavior for a $100 \%$. However, people who feel bounded by moral norms are not influenced by such instrumental reasons (Kroneberg et al. 2010; Wenzel 2004). So, if a sanction evokes moral reasons to show the desired behavior, people are likely to adhere to the rules even when the chances that they will be caught if they do not, are small (Mulder and Nelissen 2010).

Nevertheless, there may be disadvantages to the moral expressive function of sanctions, especially when people have shown the sanctioned behavior in the past. Research has shown that framing a persuasive message in moral terms can fail or even work counterproductive (Täuber et al. 2015). More specific, when people experience a failure in meeting their moral standards, this is an aversive experience as it feels like a threat to their morality. This has been shown to elicit self-protective responses (Monin 2007). For example, in a study by Täuber and Van Zomeren (2013) people were exposed to shortcomings of their own nation with regard to climate change or immigration policies. When these shortcomings were framed in moral terms, this resulted in a refusal to strive for improvement of the nation's shortcomings. Another example stems from health literature. Mulder et al. (2015) showed that people who were overweight showed more unhealthy eating behavior after exposure to a message in which obesity was presented as a moral issue than after a message that actively contradicted that obesity was a moral issue.

Thus, communicating that a particular behavior is immoral may create defensive reactions among those are showing the behavior. This is problematic when sanctions are used to induce behavioral change in people who are showing the undesired behavior. Indeed, literature on reintegrative shaming suggests that sanctions work counterproductive because they express rejection of the person (Braithwaite 1989, 2006) and other findings in criminology demonstrate that actually having received a punishment (rather than only the threat of it) evokes criminal behavior (Bernburg et al. 2006; Paternoster and Piquero 1996). A recent illustration of this is a study 
performed by Harris and Worden (2014) among police officers who had obtained a complaint. Police officers who received more severe sanctions turned out to be more likely to obtain an additional sustained complaint further on in their career compared to police officers who had not been sanctioned. Apparently the received sanction did not prevent them from behaving badly in future.

Because of the danger that a moral message communicated by a sanction may backfire, it may seem better to address people who already show the undesirable behavior in different ways than with sanctioning. Or, at least, if a sanction is used, they should be sanctioned without expressing that their behavior was morally bad. For example, one may choose to motivate people who are showing undesirable behavior by introducing a reward for changing their behavior. As discussed before, a reward is less likely to induce a moral norm than a punishment. Among people who show the undesirable behavior, it will therefore evoke less reactance.

Despite its possible dangers of inducing defensive reactions among those who already show the sanctioned behavior, it is worthwhile to strive for sanctions that evoke moral norms. After all, by inducing a moral norm, sanctions may prevent behavior to occur in the first place, and even in case of a sub-optimal surveillance system. Also, they may uphold a moral norm among people who follow the rules, making it less likely that they will be "contaminated" by those who break the rules. Moreover, if a sanction succeeds in evoking a moral norm, it becomes more likely that people openly condemn the sanctioned behavior, which contributes to further development of commonly agreed upon moral norms throughout society. This may, in the long run, make it more likely that even people who break the rule change their own behavior.

\subsection{Future research directions}

Drawing from psychological literature, this paper argued that sanctions can convey moral norms and highlighted a few factors that have been empirically shown to contribute to this moral expressive function of sanctions. Of course, there may be more factors worthy of investigation that increase the likelihood that a sanction evokes moral norms. For example, a sanction may be more successful when a rationale is given when it is introduced. If it is clear why there is a sanction and why the sanctioned behavior is regarded as "bad", it is probably more likely that people adopt the moral norm that is communicated. Also, the role of detection probability may be investigated further. From a purely deterrence perspective, it has been suggested that detection probability is more powerful than sanction severity (Jacobs and Piquero 2013; Piquero et al. 2011; Pratt et al. 2006; Varma and Doob 1998). However, does detection probability also affect moral norms? On the one hand, one could argue that a high level of surveillance may express the message that an authority regards it important to prevent the prohibited behavior. People could infer from this that the prohibited behavior is harmful and morally reprehensible, which would foster moral norms. On the other hand, financial sanctions with an extremely high detection probability are more likely to be experienced as a business transaction, which would undermine moral norms. For example, a small "late filing penalty" that it is registered and charged automatically for not paying a bill before 
an expiration date may be perceived as a compensatory sanction. Due to the $100 \%$ registration (rather than random checks), people may perceive the penalty more as a "fee", inducing them into an instrumental trade-off to either pay straight away, or pay something extra in order to postpone their payment.

Further, the question may be raised about the exact mechanisms by which sanctions shape moral norms. Do sanctions express that other people of the group morally disapprove of the behavior? Or do sanctions may simply be expressions of what the common behavior is? In other words: do sanction evoke moral norms through injunctive or descriptive norms? The distinction between injunctive and descriptive norms was made by Cialdini et al. (1991, 2006). Injunctive norms are norms that communicate what people ought to do, whereas descriptive norms are norms that communicate what people actually do. Interestingly, sanctions have the ability to contribute to either one of these norms. On the one hand, sanctions may contribute to the injunctive norm that one should not engage in the prohibited behavior. After all, when a sanction can communicate moral disapproval, as the current paper suggests, this comes down to communicating what one ought to do. On the other hand, sanctions may inadvertently contribute to a descriptive norm in favor of the prohibited behavior (Cialdini 1996; Mulder et al. 2005). For example, if a sanctioning system is installed that it is forbidden to smoke in public places, people may infer that smoking in public places is existing behavior in need of discouragement. As such, the sanction implies that there are people out there who engage in the prohibited behavior (Cialdini et al. 1991; Cialdini 1996). When it is perceived that this concerns a large group of people, the behavior may actually be regarded as acceptable (Schultz et al. 2007), which will naturally harm rather than help the development of favorable moral norms.

The research presented in the present paper suggests that a sanction will induce the desired injunctive norm as long as it is retributive, a punishment, and (reasonably) severe. Possibly, such a sanction communicates that, although there may be people who engage in the sanctioned behavior, the behavior is regarded as unacceptable by the majority of the group or society. In contrast, compensatory sanctions, rewards, or mild sanctions may actually communicate that a large group of people engage in the sanctioned behavior and that thus the behavior is "normal". This will hamper the development of a moral norm against the behavior. Whether or not this will happen may not only depend on characteristics of the sanction, but also on the contextual factor of how prevalent the sanctioned behavior was before the sanction was introduced. When a majority of individuals in one's surroundings is showing the sanctioned behavior, a sanction (even a retributive reasonably severe punishment) may backfire. It may communicate the descriptive norm that the behavior is commonly shown, and it may further be experienced as unjust. However, when only a few individuals in one's surroundings are showing the sanctioned behavior, a sanction is more likely to be experienced as an expression of an existing moral norm and will more likely contribute to the further consolidation of the norm. Further research is needed to test the exact relationships between sanction characteristics, the prevalence of the sanctioned behavior and the extent to which a sanction communicates an injunctive or descriptive norm. 


\section{Conclusion}

When policy makers install sanctioning systems to discourage undesirable behavior, it is important to consider not only the utilitarian function of the sanction, but also its possible effects on moral norms. When sanctions convey moral norms, they can make people adhere to the rules for moral rather than for instrumental reasons, which makes the sanctioning system impervious to suboptimal enforcement. I have highlighted research findings that show that sanctions are particulary successful in conveying norms when they are retributive rather than compensatory, when they come in the shape of punishments rather than rewards, and are (reasonably) severe rather than mild and installed in a fair way by a trustworthy authority. Future research focusing not only on sanction characteristics but also on contextual factors that determine whether an injunctive or descriptive norm is triggered, will paint a more complete picture of the conditions that have to be fulfilled for a sanction to have a moral expressive function.

Open Access This article is distributed under the terms of the Creative Commons Attribution 4.0 International License (http://creativecommons.org/licenses/by/4.0/), which permits unrestricted use, distribution, and reproduction in any medium, provided you give appropriate credit to the original author(s) and the source, provide a link to the Creative Commons license, and indicate if changes were made.

\section{References}

Aquino, K., \& Reed, A. (2002). The self-importance of moral identity. Journal of Personality and Social Psychology, 83(6), 1423-1440.

Balliet, D., Mulder, L. B., \& Van Lange, P. A. M. (2011). Reward, punishment, and cooperation: A metaanalysis. Psychological Bulletin, 137(4), 594-615. doi:10.1037/a0023489.

Beccaria, C. (1775). An essay on crimes and punishment. Brookline Village: Branden.

Becker, G. S. (1993). Nobel lecture: The economic way of looking at behavior. Journal of Political Economy, 101(3), 385-409. http://www.jstor.org/action/showPublication?journalCode=jpoliecon.

Bernburg, J. G., Krohn, M. D., \& Rivera, C. J. (2006). Official labeling, criminal embeddedness, and subsequent delinquency. Journal of Research in Crime and Delinquency, 43(1), 67-88.

Bilz, K., \& Nadler, J. (2009). Law, psychology, and morality. Moral Judgment and Decision Making, 50, 101-131. doi:10.1016/S0079-7421(08)00403-9.

Blasi, A. (1983). Moral cognition and moral action: A theoretical perspective. Developmental Review, 3(2), 178-210.

Blasi, A. (1984). Moral identity: Its role in moral functioning. In W. Kurtines \& J. Gewirtz (Eds.), Morality, moral behavior and moral development (pp. 128-139). New York: Wiley.

Braithwaite, J. (1989). Crime, shame and reintegration. Cambridge: Cambridge University Press.

Braithwaite, V. (2006). Is reintegrative shaming relevant to tax evasion and avoidance? In H. Elffers, P. Verboon, \& W. Huisman (Eds.), Managing and maintaining compliance (). The Hague: Boom Legal Publishers.

Carlsmith, K. M., Darley, J. M., \& Robinson, P. H. (2002). Why do we punish? Deterrence and just deserts as motives for punishment. Journal of Personality and Social Psychology, 83(2), 284-299.

Cialdini, R. B. (1996). Social influence and the triple tumor structure of organizational dishonesty. In D. M. Messick \& A. E. Tenbrunsel (Eds.), Codes of conduct: Behavioral research into business ethics. New York: Russel Sage Foundation.

Cialdini, R. B., Demaine, L., Sagarin, B. J., Barret, D. W., Rhoads, K., \& Winter, P. L. (2006). Managing social norms for persuasive impact. Social Influence, 1, 3-15. 
Cialdini, R. B., Kallgren, C. A., \& Reno, R. R. (1991). A focus theory of normative conduct: A theoretical refinement and reevaluation of the role of norms in human behavior. Advances in Experimental Social Psychology, 24, 201-234.

Cooter, R. (1998). Expressive law and economics. Journal of Legal Studies, 27(2), 585-608.

Darley, J. M., \& Pittman, T. S. (2003). The psychology of compensatory and retributive justice. Personality and Social Psychology Review, 7(4), 324-336.

Dawes, R. M. (1980). Social dilemmas. Annual Review of Psychology, 31, 169-193.

Deci, E. L., Koestner, R., \& Ryan, R. M. (1999). A meta-analytic review of experiments examining the effects of extrinsic rewards on intrinsic motivation. Psychological Bulletin, 125(6), 627-668.

Depoorter, B., \& Vanneste, S. (2005). Norms and enforcement: The case against copyright law. Oregon Law Review, 84, 1127-1179.

Ellsworth, P. C., \& Gross, S. R. (1994). Hardening of the attitudes: Americans' views on the death penalty. Journal of Social Issues, 50(2), 19-52. doi:10.1111/j.1540-4560.1994.tb02409.x.

Fehr, E., \& Falk, A. (2001). Psychological foundations of incentives. European Economic Review, 46, $687-724$.

Feldman, Y. (2009). The expressive function of trade secret law: Legality, cost, intrinsic motivation, and consensus. Journal of Empirical Legal Studies, 6(1), 177-212. doi:10.1111/j.1740-1461.2009. 01141.x.

Gneezy, U., \& Rustichini, A. (2000). A fine is a price. Journal of Legal Studies, 29, 1-17.

Goslinga, S., \& Denkers, A. (2009). Motives for non-compliance: A study among business entrepreneurs. Gedrag \& Organisatie, 22(1), 3-22.

Harris, C. J., \& Worden, R. E. (2014). The effect of sanctions on police misconduct. Crime \& Delinquency, 60(8), 1258-1288. doi:10.1177/0011128712466933.

Jacobs, B., \& Piquero, A. R. (2013). Boundary-crossing in perceptual deterrence: Investigating the linkages between sanction severity, sanction certainty, and offending. International Journal of Offender Therapy and Comparative Criminology, 57(7), 792-812. doi:10.1177/0306624X12443944.

Kant, I. (1797/1991). The metaphysics of morals. Cambridge, UK: Cambridge University Press.

Kroneberg, C., Heintze, I., \& Mehlkop, G. (2010). The interplay of moral norms and instrumental incentives in crime causation*. Criminology, 48(1), 259-294.

Kurz, T., Thomas, W. E., \& Fonseca, M. A. (2014). A fine is a more effective financial deterrent when framed retributively and extracted publicly. Journal of Experimental Social Psychology, 54, 170-177. doi:10.1016/j.jesp.2014.04.015.

McAdams, R. H. (2000). An attitudinal theory of expressive law. Oregon Law Review, 79(2), 339.

McFatter, R. (1982). Purpose of punishment: Effects of utilities of criminal sanctions on perceived appropriateness. Journal of Applied Psychology, 67(3), 255-267.

Monin, B. (2007). Holier than me? Threatening social comparison in the moral domain. Revue Internationale De Psychologie Sociale, 20(1), 53-68.

Mulder, L. B. (2008). The difference between punishments and rewards in fostering moral concerns in social decision making. Journal of Experimental Social Psychology, 44, 1436-1443.

Mulder, L. B. (2009). The two-fold influence of sanctions on moral norms. In D. De Cremer (Ed.), Psychological perspectives on ethical behavior and decision making (pp. 169-180). Charlotte, NC: Information Age Publishing.

Mulder, L. B., \& Nelissen, R. (2010). When rules really make a difference: The effect of cooperation rules and self-sacrificing leadership on moral norms in social dilemmas. Journal of Business Ethics, 95, 57-72. doi:10.1007/s10551-011-0795-z.

Mulder, L. B., Rupp, D. E., \& Dijkstra, A. (2015). Making snacking less sinful: (Counter-)moralising obesity in the public discourse differentially affects food choices of individuals with high and low perceived body mass. Psychology \& Health, 30(2), 233-251. doi:10.1080/08870446.2014.969730.

Mulder, L. B., van Dijk, E., Wilke, H. A. M., \& De Cremer, D. (2005). The effect of feedback on support for a sanctioning system in a social dilemma: The difference between installing and maintaining the sanction. Journal of Economic Psychology, 26(3), 443-458. http://www.elsevier.com/wps/find/ journaldescription.cws_home/505589/description\#description.

Mulder, L. B., Verboon, P., \& De Cremer, D. (2009). Sanctions and moral judgments: The moderating effect of sanction severity and trust in authorities. European Journal of Social Psychology, 39(2), 255-269.

O’Gorman, R., Wilson, D. S., \& Miller, R. R. (2005). Altruistic punishment and helping differ in sensitivity to relatedness, friendship, and future interactions. Evolution and Human Behavior, 26, 375-387. 
Paternoster, R., \& Piquero, A. (1996). Reconceptualizing deterrence: An empirical test of personal and vicarious experiences. Journal of Research in Crime and Delinquency, 32(2), 251-286.

Piquero, A. R., Paternoster, R., Pogarsky, G., \& Loughran, T. (2011). Elaborating the individual difference component in deterrence theory. In Hagan, J. (Ed.), (pp. 335-360) Associate Editors: Kim Lane Scheppele and Tom R. Tyler. Palo Alto, Calif.: Annual Reviews.

Pratt, T. C., Cullen, F. T., Blevins, K. R., Daigle, L. E., \& Madensen, T. D. (2006). The empirical status of deterrence theory: A meta-analysis. In F. T. Cullen, J. P. Wright, K. R. Blevins (Eds.), (pp. 367-395). Piscataway, NJ, US: Transaction Publishers.

Scholz, J. T., \& Pinney, N. (1995). Duty, fear, and tax compliance: The heuristic basis of citizenship behavior. American Journal of Political Science, 39(2), 490.

Schultz, P. W., Nolan, J. M., Cialdini, R. B., Goldstein, N. J., \& Griskevicius, V. (2007). The constructive, destructive, and reconstructive power of social norms. Psychological Science, 18(5), 429-434.

Täuber, S., \& Van Zomeren, M. (2013). Outrage towards whom? Threats to moral group status impede striving to improve via out-group-directed outrage. European Journal of Social Psychology, 43(2), 149-159. doi:10.1002/ejsp.1930.

Täuber, S., Van Zomeren, M., \& Kutlaca, M. (2015). Should the moral core of climate issues be emphasized or downplayed in public discourse? Three ways to successfully manage the doubleedged sword of moral communication. Climatic Change, 130(3), 453-464. doi:10.1007/s10584-0141200-6.

Tenbrunsel, A. E., \& Messick, D. M. (1999). Sanctioning systems, decision frames, and cooperation. Administrative Science Quarterly, 44(4), 684-707.

Thøgersen, J. (2008). Social norms and cooperation in real-life social dilemmas. Journal of Economic Psychology, 29(4), 458-472. doi:10.1016/j.joep.2007.12.004.

Tjosvold, D. (1995). Effects of power to reward and punish in cooperative and competitive contexts. Journal of Social Psychology, 135(6), 723-736.

Torgler, B., \& Schneider, F. (2005). Attitudes towards paying taxes in austria: An empirical analysis. Empirica, 32(2), 231-250.

Varma, K. N., \& Doob, A. N. (1998). Deterring economic crimes: The case of tax evasion. Canadian Journal of Criminology, 40(2), 165-184.

Verboon, P., \& van Dijke, M. (2011). When do severe sanctions enhance compliance? The role of procedural fairness. Journal of Economic Psychology, 32(1), 120-130. doi:10.1016/j.joep.2010.09. 007.

Warr, M., Meier, R. F., \& Erickson, M. L. (1983). Norms, theories of punishment, and publicly preferred penalties for crimes. Sociological Quarterly, 24(1), 75-91.

Watamura, E., Wakebe, T., Fujio, M., Itoh, Y., \& Karasawa, K. (2014). The automatic activation of retributive motive when determining punishment. Psychological Studies, 59(3), 236-240. doi:10. 1007/s12646-014-0269-3.

Wenzel, M. (2004). The social side of sanctions: Personal and social norms as moderators of deterrence. Law and Human Behavior, 28(5), 547-567.

Williams, K. R., \& Hawkins, R. (1986). Perceptual research on general deterrence: A critical review. Law and Society Review, 20(4), 545-572.

Wiltermuth, S. S., \& Flynn, F. J. (2013). Power, moral clarity, and punishment in the workplace. Academy of Management Journal, 56(4), 1002-1023. doi:10.5465/amj.2010.0960.

Wit, A., \& Wilke, H. A. M. (1990). The presentation of rewards and punishments in a simulated social dilemma. Social Behaviour, 5(4), 231-245.

Yanagida, M., \& Fujii, S. (2004). The psychological effects of institution of law on moral obligation. In Proceedings of master thesis of department of civil engineering. Tokyo: Tokyo Institute of Technology. 